\title{
TEMPERATURE-INDUCED SHAPE MEMORY CHARACTERISTICS OF EPOXY RESIN-BASED FABRIC-REINFORCED COMPOSITES
}

\author{
J.Karger-Kocsis ${ }^{1,2, a}$ \\ ${ }^{1}$ Department of Polymer Engineering, Faculty of Mechanical Engineering, Budapest University of \\ Technology and Economics, Muegyetem rkp. 3., H-1111 Budapest, Hungary \\ ${ }^{2}$ MTA-BME Research Group for Composite Science and Technology, Muegyetem rkp. 3., H-1111 \\ Budapest, Hungary \\ akarger@pt.bme.hu
}

Keywords: shape memory polymer, epoxy resin, composite, bending mode, shape fixity, shape recovery

\begin{abstract}
Shape memory characteristics of woven glass and carbon fiber fabric reinforced epoxy resin-based composites were assessed in bending mode using a dynamic mechanical analyzer. The reinforcement strongly improved the recovery stress but impaired the bending deformability. Composites with asymmetric fabric lay-up showed better performance when the reinforced section experienced local tension than compression during flexural loading.

\section{Introduction}

A shape memory polymer (SMP) is an actively moving polymer, which recovers its original shape from a previously programmed, temporary shape upon an external stimulus. The temporary shape can be achieved by mechanical loading in presence of the external stimulus and fixed by removing or changing this stimulus. The external stimulus is often a temperature increment, which can be triggered both by direct and indirect heating. The shape memory effect is induced, when the SMP reaches a critical temperature, called transformation temperature $\left(\mathrm{T}_{\text {trans }}\right)$. This agrees with the glass transition temperature $\left(\mathrm{T}_{\mathrm{g}}\right)$ for crosslinked thermosets, such as epoxy resins (EP). SMPs may have many advantages (easy processability, low cost, light weight, high deformability etc.) compared to shape memory alloys. However, SMPs have some limitations, from which low recovery stress is the most important problem with respect to potential applications. Increasing the low recovery stress of SMPs is the major challenge in this field nowadays.
\end{abstract}

\section{Experimental}

The preparation of the composites has been disclosed in our papers [4-5]. Their shape memory characteristics were determined in 3-point bending tests in a dynamic mechanical analyzer (DMA) [4-5].

\section{Results and Discussion}

From three dimensional representation of the shape memory cycle (Fig. 1) it can be seen very well that the shape fixity decreased, but the deformation/recovery stresses increased when 38 vol.\% GF woven fabric (four layers) was incorporated into the EP matrix. Parallel to that the bending strain was, however, markedly reduced compared to the neat EP. 


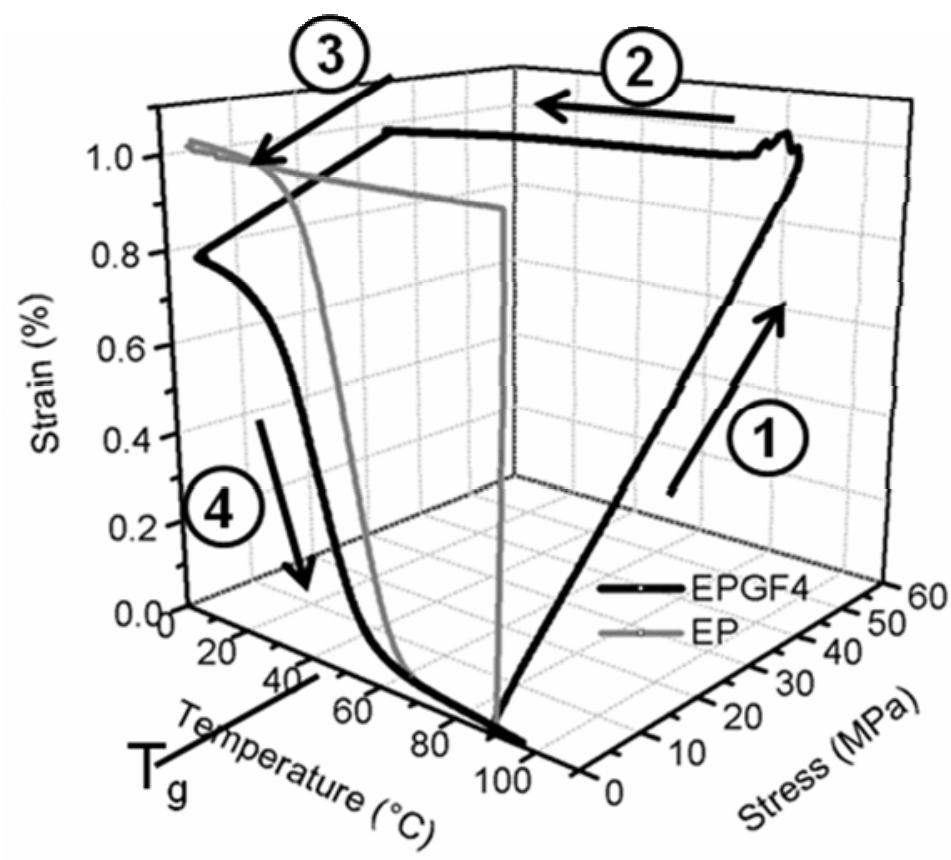
(1) Shaping
(2) Shape fixing
(3) Deloading
(4) Recovery

Figure 1: Three dimensional temperature - stress - strain plots for EP and EPGF4. Note: EPGF4 contains 4 GF woven fabric layers

Next we have checked how the layering of CF fabrics affected the shape memory response. Asymmetric layering was achieved by incorporating two and four CF fabric layers whereby setting a resin- and reinforcement-rich layer ratio of $1 / 4$ and 1/2, respectively (cf. Fig. 2). The maximum strain set in these EPCF systems was $2.5 \%$, i.e. markedly higher than for EPGF (1\%). Schematic picture of the samples' cross sections along with their coding is given in Figure 2 . The related specimens with two (2) and four CF fabric layers (4) were subjected to flexure from both sides, i.e. from the top ( $\mathrm{t}$ ) and bottom (b), respectively (cf. Fig. 2).

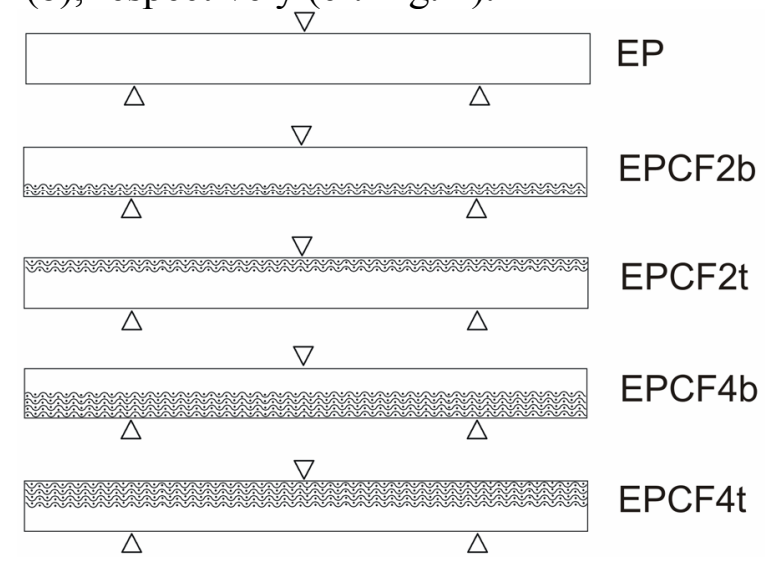

Figure 2: Three-point bending arrangements of the EPCF samples and their coding

Shape memory behaviour was assessed in both unconstrained and fully constrained tests also in the DMA device, and the corresponding tests comprised up to 5 cycles. Results from the unconstrained (stress free) and constrained (constant strain) shape memory tests are summarized for $\mathrm{EP}$ and EP/CF fabric composites in Table 1. The shape fixity ratio $\left(\mathrm{R}_{\mathrm{f}}\right)$ was improved for EPCF2b and worsened in other cases compared to EP. The shape recovery ratio $\left(\mathrm{R}_{\mathrm{r}}\right)$ decreased remarkably for EPCF2t, but not changed for EPCF2b. 


\begin{tabular}{lccccc} 
Properties & EP & EPCF2b & EPCF2t & EPCF4b & EPCF4t \\
\hline $\mathrm{R}_{\mathrm{f}}(\%)$ & 101 & 104 & 93 & 99 & 94 \\
$\mathrm{R}_{\mathrm{r}}(\%)$ & 103 & 103 & 93 & 100 & 100 \\
$\sigma_{\text {load }}(\mathrm{MPa})$ & 0.7 & 3.2 & 2.9 & 9.6 & 8.5 \\
$\sigma_{\text {fix }}(\mathrm{MPa})$ & 0.0 & 0.0 & 8.9 & 0.1 & 7.9 \\
$\sigma_{\text {rec }}(\mathrm{MPa})$ & 0.7 & 3.3 & 2.9 & 9.7 & 8.5
\end{tabular}

Table 1 Shape memory characteristics of the EP and asymmetrically reinforced composite specimens

For EP, EPCF2b and EPCF4b cyclic unconstrained shape memory tests were also performed. Results showed that the shape fixity and shape recovery ratios did not change significantly over five consecutive cycles. Recovery stress was strongly enhanced by the $\mathrm{CF}$ fabric reinforcement. As expected the more CF was incorporated, the higher the recovery stress was. The shape fixity and recovery ratios changed marginally as a function of $\mathrm{CF}$ reinforcement content. Recovery stress is higher when the CF fabric rich layers are on the tension than on the compression side of the bent specimens. For this arrangement the shape memory performance over five repeated cycles did not change practically. The shape fixity ratios were smaller when the CF fabric rich layers experienced local compression than tension. This was traced to a spring back effect owing to the thermal expansion mismatch between the matrix and CF-rich layers.

\section{Conclusion}

The shape memory characteristics of EP composites with woven GF and CF reinforcements, also in asymmetrical lay-up, were assessed in three point bending mode in a DMA device and compared to those of the parent EP. It was found that fabric reinforcement strongly enhanced the loading and recovery stresses. This happened, however, at cost of the bending strain. To overcome this difficulty the incorporation of natural fiber-based textile structures is recommended. To position the reinforcement on the tension- rather than on the compression-loaded side is more straightforward. Suitable non-destructive methods should be adapted to check eventual damage of the composites during their (repeated) bending deformations in the shape memory tests

\section{Acknowledgements}

The work reported here was supported by the Hungarian Research Fund (OTKA NK 83421) and partly also by the New Széchenyi Plan (TÁMOP-4.2.2.A-11/1/KONV-2012-0036).

\section{References}

[1] I. A. Rousseau, Challenges of shape memory polymers: A review of the progress toward overcoming SMP's limitations, Polym. Eng. Sci., 48 (2008) 2075-2089.

[2] X. Lan, Y. Liu, H. Lv, X. Wang, J. Leng and S. Du, Fiber reinforced shape-memory polymer composite and ist application in a deployable hinge, Smart Mater. Struct., 18 (2009) 024002/1024002/6.

[3] J. Ivens, M. Urbanus and C. De Smet, Shape recovery in a thermoset shape memory polymer and its fabric-reinforced composites, Express Polym. Lett., 5 (2011) 254-261.

[4] M. Fejős, G. Romhány and J. Karger-Kocsis, Shape memory characteristics of glass fiber reinforced epoxy composite, J. Reinf. Plast. Compos., 31 (2012) 1532-1537.

[5] M. Fejős M and J. Karger-Kocsis, Shape memory performance of asymmetrically reinforced epoxy/carbon fiber fabric composites in flexure, Express Polym. Lett., 7 (2013) 528-534 